\title{
Shrek: mimese, consumo e/ou aprendizagem
}

\author{
Malena Segura Contrera \\ Ivan Fortunato
}

Resumo: O artigo investiga a repercussão da personagem de animação Shrek, considerando sua natureza imaginária e as relações que os meios de comunicação estabelecem entre imaginário e consumo. Pensando no processo de espelhamento e na centralidade dos processos miméticos para a constituição da identidade social, o artigo busca investigar não apenas a repercussão da personagem Shrek, mas também possíveis efeitos que o tratamento dado à personagem possa ter, como o hiperconsumo e a infantilização.

Palavras-chave: mimese; mídias; Shrek; imaginário

Abstract: Shrek: mimesis, consumption and/or learning - This article studies the repercussion of the animated cartoon character Shrek, considering his fictional nature and the relationship between consumption and the imaginary established by the mass media. With regard to the mirroring process and the centrality of mimetic processes in the formation of social identity, this paper seeks to examine not only the impact of the Shrek character but also the possible effects resulting from the treatment given to this cartoon character, such as hyperconsumption and infantilization.

Keywords: mimesis; media; Shrek; imaginary

\section{Introdução}

O processo de eletrificação do mundo ocorrido no século XX, mais do que possibilitar a produção em série de objetos de consumo concretos e simbólicos, operou algo que $\mathrm{E}$. Morin chamou de "industrialização do espírito", ou seja, a homogeneização dos gostos e dos hábitos; as práticas miméticas alcançaram então um caráter de padronização que as afastaram das estratégias de sociabilidade e as aproximaram da seriação comportamental. A centralidade social que hoje os meios de comunicação eletrônicos possuem desde o início do século XX desempenha o papel de criar multidões e, segundo Madrid (1986, p. 59), é reflexo da intensa circulação de significados e conteúdos que "tem um impacto sobre 
as consciências do povo" ao estabelecer uma "rede de relações ideológicas de distintas dimensões (macro e microrredes) que articulam simbólica, afetiva e racionalmente", mas articulam segundo seus próprios padrões de imagem e funcionamento.

Ao lado da padronização, a sociedade mediática se caracteriza pela proliferação das emissões (CONTRERA, 2010). A marca da sociedade contemporânea, nesse sentido, é o excesso - sempre mais do mesmo.

O vazio simbólico gerado pelo excesso intensifica a busca individual por aquilo que em outro momento (2005, p. 118) chamamos de "paraísos artificiais tecnologicamente criados no espaço privado da casa-fortaleza". Esses paraísos são ambientes imagéticos (e imaginários) e neles as imagens mediáticas são preferidas em detrimento de vivências concretas, em uma enorme ilusão de controle, estratégia psicológica infantil que revela a fragilidade das condições de vida nas megassociedades contemporâneas.

Mas como se escolhe as imagens mediáticas que povoarão nosso particular castelo imaginário?

As imagens estão à venda, e vendem tudo que se possa sonhar. Mas nem tudo está em oferta, o mercado sabe quais os sonhos que sonhamos. A aceitação de uma personagem, de uma história ou de um produto tem muito mais a ver com a sua representatividade no imaginário cultural, inclusive a partir da apresentação de elementos de culturas arcaicas, do que com uma mera imposição mercadológica; o mercado, por sua vez, apropria-se de conteúdos arcaicos significativos e cria produtos que ecoam no imaginário. Essas imagens serão aquelas que venderão por mais tempo, que irão além de uma simples ação sazonal que prevê uma obsolescência predeterminada. É sobre um desses casos que o presente texto se ocupa.

Assim, em 2001, através das telas do cinema, surge uma dessas imagens duradouras: a personagem Shrek, do filme animado de mesmo nome. Shrek merece uma análise por sua representatividade na mídia, porque sua reverberação indica que a sociedade acolheu a personagem: alto faturamento, prêmios diversos e indicações (incluindo o Oscar) e, além de se tornar uma animação com quatro longas-metragens (lançados entre 2001 e 2010), tornou-se multiplataforma ao entrar na televisão com um especial de Natal e na internet com um website interativo próprio.

\section{Shrek e os contos de fada}

Shrek se tornou um fenômeno dos mais interessantes do começo do século XXI: talvez seja o monstro mais amado pelas crianças. Horrendo à primeira vista, esse gigantesco ogro tem um coração do tamanho do sistema solar e é só bondade. Impossível resistir a ele (GONÇALO JUNIOR, 2008, p. 223). 
Shrek já foi objeto de estudo, no Brasil, em dissertações de mestrado. Em "O ogro que virou príncipe", Correa (2006) analisa a animação Shrek como uma paródia aos contos de fada. Na interpretação da autora, a utilização do ogro como protagonista teve o propósito de criar um efeito de estranhamento, já que os heróis de contos de fada são - essencialmente - príncipes encantados. Para ela, Shrek, o herói de aparência não padronizada e com hábitos não civilizados, teria, como pano de fundo, uma mensagem baseada na moral e nas relações humanas, como nos conhecidos ditados populares: não julgue um livro pela capa ou as aparências enganam.

Em outro trabalho, Silva (2007) identifica a animação Shrek como uma adaptação do moderno conto de fadas de William Steig; retomando a noção de conto de fadas moderno, a autora aborda a questão das relações com outras personagens infantis e outros contos, ressaltando o tom de paródia dominante na animação.

Tanto Correa quanto Silva insistem na relação da animação Shrek com os contos de fadas. Essa relação é clara na animação, que possibilita inúmeras intertextualidades e, cena a cena, é possível buscar remissões a contos de fadas, ou outro desenho animado, ou filme, ou situação que foi divulgada na mídia. Neste trabalho, não negamos as remissões nem as referências aos contos de fadas: castelos, rei/rainha, cavaleiros, dragões e a narrativa em torno da busca pelo final feliz do casal príncipe/princesa protagonistas e suas expiações. No entanto, nossa análise se interessou em mergulhar na representatividade das características do protagonista, que é um ogro não convencional.

Shrek é um ogro que não assusta ${ }^{1}$, que é sedutor: sua configuração estética se aproxima dos dóceis e inocentes animais humanizados e com gosto de rosa da Disney, na proposição de Dorfman e Mattelard (1997); sua narrativa o coloca como o herói (CAMPBELL, 1999); o cômico que perpassa suas aventuras estimula o humor, faculdade catártica que atrai as atenções para a tela.

\section{Shrek e seu mercado consumidor}

[...] em vez de sentir medo quando viram essas superproduções, as crianças tiveram uma reação contrária: e correram às lojas de brinquedo para ter as esquisitas figuras em seus quartos (GONÇALO JUNIOR, 2008, p. 23).

Shrek é um dos desenhos animados mais representativos deste início de século, tornando-se figura importante da indústria cultural (cf. ADORNO e HORKHEIMER, $1985^{2}$ ), que não apenas vende seus desenhos animados (em forma de bilhetes de cinema

Para compreender a relação entre Shrek e seu arquétipo, o ogro, ver Fortunato, 2009.

2 Conforme conceituação de Adorno e Horkheimer (1985). Os autores, na introdução de seu livro, explicam:

"Mas como a invocação de seu próprio caráter comercial, de sua profissão de uma verdade atenuada, há muito se tornou uma evasiva com a qual ela tenta furtar-se à responsabilidade pela mentira que difunde, nossa análise atém-se à pretensão, objetivamente inerente aos produtos, de serem obras estéticas e, por isso mesmo, uma configuração da verdade. Ela revela, na nulidade dessa pretensão, o caráter maligno do social. O segmento sobre a indústria cultural é ainda mais fragmentário do que os outros". 
e DVDs), mas que também utiliza sua imagem para venda de produtos que estampam Shrek expandindo a venda para milhares. Considerando os processos psicoativos de projeção e identificação relacionados ao ato do consumo, podemos imaginar o impacto que a personagem Shrek causou.

Originalmente, desenhos animados, cinema animado e história em quadrinhos são produtos infantis, mas há uma dinâmica em sua produção, conforme explica Morin (1987, p. 39), que torna essa afirmação incoerente. Segundo o autor, porque criada pela indústria cultural, o mundo animado é uma espécie de preparação para a vida adulta, no sentido da formação de consumidores; "o fosso que separa o mundo infantil do mundo dos adultos tende a desaparecer". Vemos, nesse caso, a plena realização do prognóstico que Morin fez em 1987, e, nesse sentido, fica evidente como hoje a criação mediática para o mundo infantil "tornou-se instrumento de aprendizagem para a cultura de massa".

É importante destacar que, porque há uma tendência à personalização e/ou à individualização de produtos e serviços, alguns têm defendido o fim da cultura de massas. Entretanto, não resta dúvida de que o fator de massificação que atua contemporaneamente não é o produto ou o serviço em si, mas a própria ideia de personalização. O culto à ideia de identidade e personalidade foi uma criação estética da cultura de massas de tal forma introjetada que, mesmo que não tenhamos mais o domínio do tradicional formato da comunicação de massas, com o advento da web e de suas reverberações, ainda levará algum tempo para reinventarmos outra estética. Continuamos a assistir ao processo no qual ser diferente significa ser igual, e todos querem consumir incessantemente produtos com a sua cara.

A produção industrial/cultural infantil³, também tem reflexo na população adulta, que consome os produtos originalmente criados para as crianças. Assim, enquanto a produção da indústria cultural para o mercado infantil prepara a criança para o ingresso no mercado consumidor adulto, essa produção possibilita, ao mesmo tempo, que o adulto resgate alguns elementos de sua própria infância; ao consumir esses produtos ele revela uma forma de fixação em alguns estereótipos do universo infantil.

Shrek é um exemplo desses produtos criados para o mercado infantil que gera consumo e desperta o interesse também nos adultos. Isso porque as personagens principais da animação carregam elementos que estão presentes no repertório do público, que são elementos do imaginário; essa relação, afirma Muniz Sodré (1972, p. 63), amplia a comunicação. E, quanto mais há comunicação em seu sentido original, mais há o estabelecimento de vínculos. No caso de Shrek, especificamente, esses vínculos têm relação direta com a personagem e são estabelecidos a partir do movimento identificação-projeção. Esse movimento foi apontado e amplamente discutido por Morin (2000; 1987), que explica que:

3 Há importante trabalho desenvolvido, no Brasil, pelo Instituto Alana que, preocupado com as questões do consumo/ consumismo infantil, flagra os excessos em documentário disponível na internet, inclusive para download, no sítio: <http://www.alana.org.br/CriancaConsumo/Biblioteca.aspx?v=8\&pid=40> Acesso em: 28 mar. 2011. 
Podemos adiantar que uma cultura constitui um corpo complexo de normas, símbolos, mitos e imagens que penetram o indivíduo em sua intimidade, estruturam os instintos, orientam as emoções. Esta penetração se efetua segundo trocas mentais de projeção e de identificação polarizadas nos símbolos, mitos e imagens da cultura como nas personalidades míticas ou reais que encarnam os valores (os ancestrais, os heróis, os deuses) (MORIN, 1987, p. 15)

A fala de Morin mostra que o movimento de projeção-identificação precisa sempre da mediação de outros indivíduos. No entanto, a mediação se dá pela simbólica presente na natureza da personagem que é representativa de conteúdos de um imaginário culturalmente partilhado. Essa relação de projeção-identificação aparece, conforme explica Metz (1980), nas telas do cinema, e permitem que a audiência estabeleça vínculo com o que é exibido e/ou - pela sua característica cumulativa - com os elementos arcaicos do imaginário. Especificamente sobre as animações, parece que a presença de toda a ritualística existente no cinema (a sala escura, a fantasia, a magia, o movimento, as cores), mas principalmente a presença dos elementos do imaginário e o movimento de projeção-identificação, é que motiva e perpetua a existência de desenhos animados.

Há tempos vimos discutindo $(2003 ;$ 1996) esse processo que ocorre na mídia de massa, e sua capacidade de veicular diferentes fenômenos do imaginário sempre a partir de uma mesma estética e de uma narrativa padronizadas. Antes, já nos referimos a essa simplificação - que tem sempre o propósito de se ajustar às leis do mercado da indústria cultural - do mito midiático. Nesse sentido, os símbolos e as imagens da dinâmica projeção-identificação são disseminados pela comunicação de massa (quase) sempre a partir de um produto seriado, padronizado, gerando apelo em um grande número de indivíduos, movimentando as vendas. Aliás, vemos aqui claramente o processo pelo qual a noção de indivíduo desaparece na sociedade contemporânea, restando somente a de consumidor/cliente (CANCLINI, 1999; FEATHERSTONE, 1995; BAUDRILLARD, 1991; BAUMAN, 2008).

Ocupamo-nos agora de aprofundar essa questão de identificação na personagem Shrek - que é consumida por crianças, mas também por adultos. A análise recai na busca por elementos universais projetados pela personagem, que amplificam sua identificação, principalmente pela faculdade mimética, inerente ao ser humano. Na personagem, esses elementos são expressos por uma fase do desenvolvimento humano, que é justamente a passagem entre o ser primitivo e o ser civilizado.

\section{A identificação com Shrek - processos miméticos}

O imaginário não é, assim, uma vivência subjetiva e passiva, mas um território de potências ativas (SODRÉ, 1994, p. 107). 
Em epígrafe, Muniz Sodré expressa a potencialidade do imaginário na criação humana. Sendo o imaginário uma instância cumulativa e produtora/reprodutora de cultura, acredita-se que os produtos culturais (em especial os heróis de sucesso - entendido como aqueles que impactam grande público) carregam atualizações de conteúdos arcaicos, em especial aqueles dos mitos, que representam o homem universal.

Há inegável presença de Shrek no mercado consumidor, e tamanho é o sucesso da personagem que encontramos Shrek com os demais bonecos gigantes do carnaval de Olinda, Pernambuco, uma das mais representativas festas brasileiras. São tantas as situações nas quais Shrek marca sua presença que se torna evidente que a personagem rompeu completamente com a sua figura original (que é o ogro devorador), migrando para o universo do cotidiano. Vimos anteriormente (2010) que é principalmente pelo humor que a personagem consegue se desvincular desse traço canibal. No entanto, o que nos interessa aqui é reunir características de Shrek, como personagem, que possibilitam o movimento projeção-identificação que discutimos acima.

Muniz Sodré (1987) aprofundou a reflexão acerca da relação entre as telas da mídia e o espelho e, em uma análise que se vale da teoria psicanalítica, analisa dessa dinâmica de projeção-identificação: "esse processo identificatório tem nas crianças os seus melhores agentes [...] para as crianças, os modelos normativos ou heroicos veiculados podem colocarse como objetos ideais, referentes a um eu ideal, em concorrência com as figuras parentais".

Pela narrativa, vimos em Shrek a figura arquetípica do herói (CAMPBELL, 1995), e é preciso lembrar que o herói está na narrativa, e jamais na estética. Ainda que a presença da jornada do herói seja importante na questão de identificação com Shrek, ela não é suficiente para justificar a representatividade da personagem. Há que se cavar mais fundo para encontrarmos o que há em Shrek que o diferencia de tantos outros heróis-clássicos disponíveis no cinema, na televisão e em outros veículos, como quadrinhos e livros.

Há em Shrek importante processo de aprendizagem que, na animação, não é expresso, mas incorporado à personagem. Esse processo está intimamente ligado à faculdade inerente ao ser humano de adaptar suas condutas e torná-las semelhantes aos comportamentos de outros. Trata-se da mimese, que pode ser entendida inicialmente como simples imitação, mas que na realidade vai além, possibilitando a criação ou recriação dos elementos comuns, indispensáveis para o processo de sociabilidade humana. A mimese assume importância central no processo de sociabilidade e funciona muito bem para o desenvolvimento do que Norbert Elias (1992) aponta como uma das estratégias criadas pela civilização para fazer triunfar a vida em comum: o estabelecimento de elementos comuns que visam evitar o confronto constante com os próximos diferentes, servindo de verdadeira estratégia de camuflagem e adaptação diante dos ambientes potencialmente hostis, onde estariam os "predadores". Comportamentos mimeticamente aprendidos servem para apaziguar as tensões, já que o mimetismo é uma estratégia de adaptação

4 Claro que a consideração de Elias (1992) é válida, mesmo sabendo que a urbe não resolveu todos os problemas de sobrevivência, não civilizou totalmente a condição humana (vide holocausto, por exemplo), muito menos venceu as intempéries naturais. 
ao grupo. Elias (1992, p. 113) propõe que "a esfera mimética oferece uma vez mais a oportunidade, por assim dizer, de um novo 'desanuviar' no seio da sociedade, que, pelo contrário, na vida social comum possui um conteúdo uniforme".

Segundo Paul Ricoeur (1994, p. 101), o início da mimese está na imitação como forma de "pré-compreender o que ocorre com o agir humano: com sua semântica, com sua simbólica, com sua temporalidade". Ao explicar que o objetivo da mimese é compreender o sentido e o simbolismo dos atos, o autor faz uma releitura do conceito trazido por Aristóteles e afirma que se deve excluir a noção de mera cópia ou réplica do comportamento original. "A imitação ou a representação", explica Ricoeur (1994, p. 101), "é uma atividade mimética enquanto produz algo, a saber, precisamente a disposição dos fatos pela tessitura da intriga [...] tem só um espaço de desenvolvimento: o fazer humano". Walter Benjamin (1985) já afirmara que não há imitação na mimese e que essa faculdade está presente em jogos e brincadeiras infantis - é o que explica Huizinga (1996, p. 3) quando afirma que "é no jogo e pelo jogo que a civilização surge e se desenvolve".

Nessa direção, seguem Gebauer e Wulf (2004, p. 21) explicando que a mimese é mais do que a simples imitação, mas a capacidade humana de produzir semelhanças, que "desempenha uma função em quase todas as áreas humanas da ação, da imaginação, do falar e do pensar, e representa uma condição imprescindível à vida social". A mimese, segundo os autores, é alimentada pela mídia, que traz imagens modeladoras da realidade e, nessa direção, indicam que há um processo de aprendizagem social mediado pelas produções culturais veiculadas pela televisão e pelo cinema. A seguinte passagem de seu livro explica essa dinâmica, bem como traz à pauta a forma como esse processo se dá no espaço dos meios de comunicação:

Surgem imagens e textos sem sujeito: a mimese torna-se autorreferente. O surgimento e o crescimento dos meios de comunicação de massa fomentam este processo. Suas imagens comportam-se mimeticamente em relação à realidade apreendida. Eles recriam a realidade, modificam-na, absorvem-na. A miniaturização e a aceleração da realidade transformam-se em um substituto para o cotidiano de experiências reais e da verdade. Para o cotidiano não é a realidade que se torna imagem, mas as imagens tornam-se realidade (GEBAUER e WULF, 2004, p. 50).

Nesse caso, essas imagens que os meios propõem não são recebidas apenas em seus conteúdos informativos - essas imagens são modeladoras.

Ao divulgar Shrek, a mídia apresenta um ser que é ambíguo não somente pelo aspecto ogro bonzinho (FORTUNATO, 2009), mas ao apresentar um herói que tem atitudes características de um ser não civilizado. Encontramos essas características de ser não civilizado também nos seres humanos civilizados (aqui lembramos a cumulatividade própria dos conteúdos do imaginário cultural). Essa fase não civilizada, que discutimos 
a seguir com Erich Neumann (1991), faz parte do processo humano de desenvolvimento físico e cognitivo: essa fase é expressa pelos conflitos provocados pela necessidade de agir socialmente versus o desejo de agir espontaneamente, presentes em toda a vida, mas muito mais pungentes na infância e na pré-adolescência.

Shrek, por sua vez, escancara esse desejo de agir espontaneamente segundo uma natureza que não se curvou ao processo civilizatório.

\title{
Para além do ogro engraçadinho
}

\begin{abstract}
Os Ogres têm sua origem nos húngaros. O temor causado pela sua devastadora passagem na Itália, na França e na Alemanha, e o terror por eles inspirado transforma-os em verdadeiros monstros. Esses húngaros eram chamados oigours, que, em língua românica, deu Ogres, personificação da maldade, representação das personagens monstruosas que povoam as estórias (CARVALHO, s.d., p. 88).
\end{abstract}

Em outro momento (2009), apresentamos a personagem Shrek como uma releitura da figura original do ogro, que é personificação da maldade, como explica Carvalho. Releitura pautada principalmente em aspectos que não são aceitáveis pelo discurso politicamente correto de nossa sociedade: há repulsa ao canibalismo intrínseco ao ogro original, que não pode ser veiculado em filmes de animação destinados ao público infantil. Vimos também (2010) que as atitudes repugnantes e nojentas de Shrek são mascaradas pelo humor, tornando palatáveis ao olhar da audiência ações que são publicamente rejeitadas: não se deve brincar com secreções, por exemplo.

Por trás das máscaras que escondem o ogro canibal e sem modos sociais, aparece outra figura, capaz de provocar os processos de identificação dos quais vimos falando. Essa figura ainda é Shrek, mas um Shrek que já não é somente o herói ou um ogro do avesso: a faceta da personagem que engendra esse mimetismo é representante do estágio do desenvolvimento humano que marca, justamente, a passagem do mundo infantil - não tão preocupado com os modos de ser sociais - para o mundo adulto, que muitas vezes sonega seus próprios desejos para atender às demandas da socialização.

Erich Neumann (1991) explica a ontogênese do ser humano através de estágios de desenvolvimento e que esse desenvolvimento inicia em uma fase embrionária. Essa fase embrionária é, por sua vez, dividida em duas: intra e extrauterina. O autor explica essa distinção pela fragilidade do ser humano: os nove meses no útero não são suficientes para produzir um ser autossuficiente. Assim, o amadurecimento que se inicia na barriga da mãe precisa ser completado pelo mundo exterior. Após o nascimento, Neumann (1991, p. 10) explica que "a criança vai sendo moldada pela cultura humana, uma vez que a mãe vive imersa num coletivo cultural, cujos valores e linguagem influenciam, inconscientemente, mas de modo efetivo, o desenvolvimento da criança". Essa modelagem, que segundo 
o autor inicia-se muito cedo, é sempre em nome da coletividade. Porém, ressalta Neumann (1991, p. 10) "encontramos já bem desde o início o automorfismo do indivíduo, uma necessidade de formar seu próprio ser a partir dos elementos particulares que o constituem". Portanto, o indivíduo que vai se modelando para estar em coletividade secreta, apresenta ao mesmo tempo, traços de individualismo. Esse processo é sempre conflituoso.

Paul Steiner (1989, p. 197) afirma que "a ontogênese resume a filogênese". Tal afirmação propõe uma analogia do desenvolvimento individual com o da espécie humana. Essa analogia recai sobre esses conflitos que promovem o desenvolvimento. Podemos comparar, em certa medida, a filogênese da espécie humana, do homem pré-civilizado ao homem civilizado, com a ontogênese do indivíduo. Essa comparação é apontada por Freud ao indicar que é o pudor o responsável pela transição do homem pré-civilizado ao civilizado. Freud, explica Steiner (1989, p. 199), "mostra então que é sobre o pudor que virá se enxertar o processo civilizatório [...] o pudor engendrou a limpeza bem antes que a justificativa après-coup da higiene viesse a ela se acrescentar". Assim, para Steiner (1989), a vida em civilização exige que a criança renuncie seus próprios excrementos e sua excitação genital, cuja exibição e manipulação são passíveis de punição quando levados a cabo em público.

E Shrek, em diversos momentos, brinca e diverte-se com seu cheiro e com excrementos; para ele, esse pudor civilizatório não atingiu seu repertório de comportamentos. Aquele que assiste a ele pode, em certa medida, espelhar-se nesse estágio de sua vida: a criança que vive esse momento de pudorização encontrará ressonância nas atitudes do ogro Shrek; o adulto, por sua vez, encontrará remissões a esse seu período da vida, que é doloroso pelos conflitos emocionais induzidos, mas que também pode secretar certo prazer.

A relação de espelhamento, mimética, que o homem contemporâneo (com sua identidade volátil) estabelece com os meios de comunicação estimula o fascínio pelos gestos do ogro e sua estética, que transita entre o grotesco e o humor. Assim, as relações de mimese que são estabelecidas com a personagem têm raiz no movimento projeçãoidentificação principalmente porque Shrek vai expressar atitudes de uma fase da infância que é justamente a passagem para um mundo não mais infantil. Isso se torna ainda mais evidente na animação por meio do desenrolar da trama na qual Shrek, aos poucos, também vai se civilizando: casa-se, tem filhos...

\section{Do objeto para a sociedade}

Desde quando monstro pede licença, seja lá para o que for? Monstro que pede licença não é monstro coisa nenhuma. Não passa de um grandessíssimo semvergonha! (LAGO, 1984, p. 10). 
Nossa análise da personagem de animação Shrek torna evidente a relevância desse ogro que estimula o consumo ${ }^{5}$ já há uma década; Shrek e seus coadjuvantes tornaram-se bonecos de plástico, de borracha ou de pelúcia, viraram jogos de tabuleiro, estamparam cadernos (e diversos materiais escolares), embalagens de guloseimas, decoração de festas... e a lista se estende. Interessante relembrar que o consumismo que a personagem provoca atinge tanto crianças quanto adultos. Desenhos são para crianças, e elas são seus principais consumidores, mas os adultos também o amam, evidenciando uma crescente infantilização (GUATTARI, 1992) que pode ser atribuída também à transição de cidadão em cliente.

Sabemos da relação de retroalimentação entre o desejo dos consumidores, suas fantasias e fragilidades, e as imagens geradas pela indústria dos meios quando busca estimular esse consumismo (BAUDRILLARD, 1991). Mas foi de fato o papel desempenhado pela mimese, sua centralidade para a cultura humana, que nos revela algo diferente sobre essa relação, porque a mimese é a primeira aprendizagem que promove os comportamentos que não têm origem na memória genética da espécie. Isto é, mamar e chorar são de ordem fisiológica, cuja fonte é herdada da espécie - por isso todos os bebês (sadios) sabem mamar. No entanto, gestos aprendidos, comportamentos, são culturais. O que a mimese explica é que o primeiro passo para essa aprendizagem cultural parte da relação de espelhamento que se estabelece com os modelos ofertados pelo grupo social, especialmente se consideramos que esses modelos se apresentam em um espaço de tanta centralidade como o da esfera mediática. No vácuo das relações parentais e interpessoais, cenário que caracteriza a sociedade contemporânea, ou seja, na ausência de figuras de referência modelares, as crianças recorrem ao seu modelador mais próximo, cotidiano as imagens mediáticas. Isso nos traz duas implicações.

Primeiramente vimos, em Shrek, que o ogro chama a atenção porque ele está em um estágio pré-pudorizado: quando sozinho em seu pântano, não há problema em soltar gases no banho e, com isso, se divertir; mas, quando vai se civilizando na narrativa, cutucar o nariz e arrotar à mesa já passa a ser condenado pelos outros à sua volta. As crianças da sociedade urbanizada e globalizada vivem o conflito da pudorização, e os adultos, que já viveram essa fase, podem sofrer um recuo nostálgico ao ver Shrek. Freud (2009; 2009b) já havia alertado para as implicações na vida adulta, inclusive social, que surgem de questões (mal) relacionadas sobre a pudorização e que estão intimamente ligadas à sexualidade, no período da infância. Assim, parece que o sucesso de Shrek representa certo processo de cristalização nessa fase, sinalizando um mal-estar.

Num segundo momento, por meio de uma reflexão mais especifica dos processos mediáticos, Shrek recebe um tratamento estético que o "adoça" e pelo qual outras figuras monstruosas e assustadoras, como nos lembra Gonçalo Junior (2008), já foram

5 Interessante destacar a diferença que Lipovetsky (2007) faz entre consumo e consumismo. Para o autor, o consumo é vital: consome-se ar, água, alimentos e outros insumos para a manutenção da vida. Já o consumismo é uma convenção social necessária para a manutenção (e expansão) do modelo capitalista. 
também transformadas em personagem de sucesso, como a Família Addams e o longametragem Monstros S.A. Esse processo torna-se contraditório, porque esse adoçamento visa neutralizar o impacto psicológico e ético do mal no imaginário infantil, que por sua vez, conforme nos explica Gerard Jones (2004), sustentado pela psicanálise infantil de Bruno Bettelheim (1976), precisa de monstros para aprender a lidar com as dificuldades intrínsecas à vida. Dessa maneira, não há monstros para dominar, transformar ou brincar de matar (JONES, 2004), apenas brinquedos para comprar e jogar fora horas depois (porque a compra não satisfaz, explica LIPOVETSKY, 2007). A progressiva infantilização, uma das marcas ético-estéticas da sociedade pós-guerra ${ }^{6}$, que surge nas teses de Guattari (1992), na vida para o consumo (BAUMAN, 2008), no hiperconsumo (LIPOVETSKY, 2007), é reafirmada pelas personagens de animação. Esse processo torna palatáveis os monstros do imaginário, colaborando para o empobrecimento do imaginário infantil.

Isso nos leva à equação: de um lado, um imaginário infantil empobrecido, do qual se retirou a tensão necessária ao desenvolvimento da consciência ética; de outro, adultos fixados em seus ritos de passagens mal vividos. Mas todos felizes consumidores, devorando o ogro que os devora.

\author{
Malena Segura Contrera é professora titular do Programa de \\ Pós-Graduação em Comunicação da Universidade Paulista; \\ é líder do Grupo de Pesquisa em Comunicação e Estudos \\ do Imaginário (UNIP) e pesquisadora Produtividade em \\ Pesquisa do CNPq. \\ malenacontrera@uol.com.br
}

Ivan Fortunato é doutorando do PPGCOM da UNIP.

\section{Referências}

ADORNO, T.; HORKHEIMER, M. Dialética do esclarecimento: fragmentos filosóficos. 2 ed. Rio de Janeiro: Jorge Zahar, 1985.

ABBAGNANO, N. Dicionário de Filosofia. 5 ed. São Paulo: Martins Fontes, 2007.

BAITELLO JUNIOR, N. O animal que parou os relógios: ensaios sobre comunicação, cultura e mídia. São Paulo: Annablume, 1999a.

BAUDRILLARD, J. A sociedade de consumo. Lisboa: Edições 70, 1991.

BAUMAN, Z. Vida para o consumo: a transformação das pessoas em mercadoria. Rio de Janeiro: Jorge Zahar, 2008.

BETTELHEIM, B. The uses of enchantment: the meaning and the importance of fairy tales. New York: Ramdom House, 1976.

6 Em referência à Segunda Guerra Mundial. 
CAMPBELL, J. O herói de mil faces. 5 ed. São Paulo: Editora Pensamento-Cultrix, 1999.

CANCLINI, N. Consumidores e cidadãos. Rio de Janeiro: UFRJ, 1999.

CARVALHO, B. V. Literatura infantil: estudos. São Paulo: s.d.

CONTRERA, M. S. Publicidade e mito. In: ; HATTORI, O. T. (Org.). Publicidade e cia. São Paulo: Thomsom/Pioneira, 2003.

Mediosfera. São Paulo: Annablume, 2010.

CORREA, A. O ogro que virou príncipe: uma análise dos intertextos presentes em Shrek. Dissertação (Mestrado em Letras). Porto Alegre: Pontifícia Universidade Católica do Rio Grande do Sul, 2006.

DA VIÁ, S. C. Televisão e consciência de classe: o trabalhador têxtil em face dos meios de comunicação de massa. Petrópolis: Vozes, 1977.

DORFMAN, A.; MATTELART, A. Para ler o pato Donald: comunicação de massa e colonialismo. Rio de Janeiro: Paz e Terra, 1977.

DURAND, G. As estruturas antropológicas do imaginário: introdução à arquetipologia geral. São Paulo: Martins Fontes, 1997.

ELIAS, N. O processo civilizador: uma história dos costumes. vol. 1. Rio de Janeiro: Jorge Zahar, 1992.

FEATHERSTONE, M. Cultura de consumo e pós-modernismo. São Paulo: Studio Nobel, 1995.

FORTUNATO, I. A estética do grotesco na animação Shrek. In: CoMtempo, São Paulo, vol. 2, p. 21-34, 2010.

Shrek, ou como o ogro devorador é devorado pela mídia de massa. In: Ghrebh, São Paulo, vol. 1, n. 14, outubro 2009. Disponível em: <http://www.cisc.org.br/revista/ghrebh/index.php?.journa $\mathrm{l}=$ ghrebh\&page=article\&op=view\&path\%5B\%5D=51 \&path\%5B\%5D=56>. Acesso em: 2 jan. 2011.

FREUD, S. Obras completas: volume VII - um caso de histeria, três ensaios sobre a sexualidade. São Paulo: Imago, 2009a.

Obras completas: volume $\mathrm{X}$ - duas histórias clínicas: o pequeno Hans e o homem dos ratos. São Paulo: Imago, 2009b.

GEBAUER, G.; WULF, C. Mimese na cultura: agir social, rituais e jogos, produções estéticas. São Paulo: Annablume, 2004.

GONÇALO JUNIOR. Enciclopédia dos monstros. São Paulo: Ediouro, 2008.

GUATTARI, F. Caosmose: um novo paradigma estético. São Paulo: Editora 34, 1992.

HUIZINGA, J. Homo Ludens: o jogo como elemento de cultura. 4 ed. São Paulo: Perspectiva, 1996.

JONES, G. Brincando de matar monstros: por que as crianças precisam de fantasia, videogames e violência de faz de conta. [São Paulo]: Editora Conrad do Brasil, [2004].

LAGO, M. O monstrinho Medonhento. 22 ed. São Paulo: Moderna, 1984.

LIPOVETSKY, G. A felicidade paradoxal: ensaio sobre a sociedade de hiperconsumo. São Paulo: Companhia das Letras, 2007.

MADRID, J. E. As tecnologias de comunicação e a transformação do estado capitalista. In: FADUL, A (Org.). Novas tecnologias de comunicação: impactos políticos, culturais e socioeconômicos. São Paulo: Summus, Intercom, 1986, p. 57-65.

METZ, C. O significante imaginário: psicanálise e cinema. Lisboa, Portugal, 1980.

MORIN, E. Os sete saberes necessários à educação do futuro. 2 ed. São Paulo/Brasília: Cortez/ 
Unesco, 2000.

Cultura de massas no século XX: o espírito do tempo 1 - neurose. 7 ed. Rio de Janeiro: Forense Universitária, 1987.

NEILL, A. S. Liberdade sem excesso. 8 ed. São Paulo: Ibrasa, 1976.

Liberdade sem medo. São Paulo: Ibrasa, 1963.

NEUMANN, E. A criança: estrutura e dinâmica da personalidade em desenvolvimento desde o início de sua formação. 4 ed. São Paulo: Editora Cultrix, 1991.

RICOEUR, P. Tempo e narrativa. vol. I. Campinas: Papirus, 1994.

SILVA. E. M. Shrek, do conto ao filme: um reino não tão distante. Dissertação (Mestrado em Letras). Universidade Federal da Paraíba, 2007.

SODRÉ, M. Sobre a vida anunciada. In: Galáxia, n. 2, 2001.

. Jogos extremos do espírito. Rio de Janeiro: Rocco, 1994.

Televisão e psicanálise. São Paulo: Ática, 1987.

1972.

. A comunicação do grotesco: um ensaio sobre a cultura de massa no Brasil. 12 ed. Petrópolis,

STEINER, P. Filogênese e nostalgia. In: FÉDIDA, P. (Org.). Comunicação e representação: novas semiologias em psicopatologia. São Paulo: Escuta, 1989, p. 195 - 227.

Artigo recebido em agosto

e aprovado em novembro de 2012. 